\title{
METHODOLOGY FOR ANALYSIS AND EVALUATION OF THE EFFECTIVENESS OF USING OUTSOURCING SERVICES IN THE BULGARIAN ARMED FORCES
}

\author{
Nikolay STEFANOV, Ilian LILOV \\ "Vasil Levski”" National Military University, Veliko Tarnovo, Bulgaria \\ niki.s@abv.bg
}

\begin{abstract}
The improvement of the outsourcing process is directly related to the planned ideas of the managing bodies of the Bulgarian Armed Forces and the initiatives to be implemented. This in turn determines the need to analyse and evaluate the efficiency of the performance of the outsourcing service. The objective is to identify possible deviations from the requirements of the client military unit and to take action to change or improve the outsourcing process. The analysis and evaluation of the efficiency of the used outsourcing services enables an overall vision of the outsourcing process and the fulfillment of the set goals. This article studies and analyses the possibilities for applying a methodology for analysis and evaluation of the effectiveness of the use of outsourcing services in the Bulgarian Armed Forces.
\end{abstract}

Keywords: methodology, analysis, evaluation, efficiency, outsourcing services

\section{Introduction}

While performing their functional obligations, Logistics officers have to evaluate the delegated task and the available resources and must organise the activity of the subordinated forces and the assets in time. The specificity of the organisation activity of Logistics officers is reflected in their cooperation with state authorities, with businesses and with nongovernmental and other bodies. [6]

The pursuit of success in the use of outsourcing services in the sphere of the Armed Forces is entirely related to certain factors, including the choice of a successful outsourcing strategy, its proper implementation, well-trained staff, properly prepared and selected specifications of the services provided, etc.

After taking into account factors like the above and the implementation of outsourcing in the structures of the Armed Forces, the question arises: "Are there returns on the invested funds when implementing outsourcing services and what is the effect of using them?". In order to answer this question, it is necessary to analyse and evaluate the effectiveness of the implementation of such services.

2. Analysis and evaluation of the effectiveness of using outsourcing services.

The process of evaluating the quality of outsourcing services begins with determining the scope of the necessary quality parameters which provide an opportunity to evaluate the service quality level. The quality of the service must meet the requirements of the users, as well as 
characterise the properties of the services in their lifecycle stages, which determine their capability to meet the specific needs of the users.

Various quality indicators could be selected for each phase of the service lifecycle. The output data for the selection of quality indicators, in most cases, are the appointment, the functions and the functional suitability of the service. [10]

Service quality indicators may be presented as two fundamentally different groups:

$\checkmark$ functional (primary) quality indicators which define the objectives, key functions and implementation of the service. It is difficult to match the composition and the content of this group since they are determined by the specific purpose and scope of each service. In general, indicators which functionally characterise the service as a whole, and indicators characterising the individual activities, technological sequence, interactions and relations, service processes, etc. could be included in this group.

$\checkmark$ non-functional (secondary) indicators which improve the primary quality indicators, increase convenience, and extend the scope of service for military personnel. Their impact may significantly alter or completely exclude the possibility and appropriateness of using the service. These include interoperability, security, reliability, efficiency, usability, suitability and mobility.

The justification of the individual groups of indicators requires maintaining a balance between primary and secondary quality indicators. Hence, the calculation of the integral quality indicator for outsourcing services is possible through the following formula: [11]

$\mathbf{K a y}=\frac{\sum_{i=1}^{n} \overline{X_{i}}+\sum_{j=1}^{m} \overline{X_{j}^{p}}}{n m}$

where:
$\mathrm{Xi}$ and $\mathrm{Xj}$ are weighted average values;

Kay - quality of outsourcing services;

$\mathrm{i}$ - functional quality indicators;

$\mathrm{j}$ - non-functional quality indicators;

$\mathrm{n}, \mathrm{m}$ - the quantity of functional and non-functional indicators;

$q$ - priority.

The values are ranked on the 10-point system based on the minimum and maximum possible quanity of the indicator. It is advisable to compare the values obtained with different outsourcing providers.

Therefore, in order to achieve the standard quality requirements of the offered outsourced services, the Bulgarian Armed Forces need to build and implement a system and policy for quality assurance and control of the outsourced services provided. The characteristic activities for that purpose are within the competence of each chief or commander. The most important of these may be:

$\checkmark$ identification and study of the specific requirements of quality standards for services produced by the external service provider;

$\checkmark$ evaluation of the service provider's capacity to meet the quality requirements;

$\checkmark$ developing strategies and plans to adapt the structures of the Armed Forces to meet the quality requirements;

$\checkmark$ building a flexible system for managing organisational behavior;

$\checkmark$ design and implementation of a highly effective control system for the input, internal processes and the final result of the service implementation in the military units, the behaviour of the personnel, the compliance of the planned and the factual indicators of the quality control system, etc.

When the effect is cost reduction, the performance of outsourcing services could be measured as follows:

$$
E \not p r=\frac{P_{\Omega} 1-P_{\pi} 0}{K+P_{\pi}}
$$

where: 

services;

Eф $r$ - effectiveness of outsourcing

Рл1 - cost of outsourcing services for the current period;

Рл0 - cost of outsourcing services for a previous period;

$\mathrm{K}$ - invested capital;

Рл - additional costs related to the maintenance of outsourcing services.

The cost reduction indicator may be used to measure the effectiveness of outsourcing services, especially when investments are made to use them.

Measuring the effectiveness through the cost reduction indicator shows that any unwarranted increase in costs or unreasonable use of capital has an immediate negative effect on the outsourcing services implementation. In most cases, this is the result of the subjective decisions of the managing bodies, of the unfamiliarity with the circumstances and the conditions of the outsourcing service.

For the Armed Forces, the determination of the effectiveness of outsourcing services on the basis of profits and aggregate costs for maintaining them is an optimal option as this expression of effectiveness reflects all conditions - objective or subjective, correctly or incorrectly taken management decisions, improvement or deterioration of the results of the use of outsourcing services in the structures of the Bulgarian Armed Forces.

The overall process of outsourcing a service is associated with a very important indicator of the evaluation of the service effectivess, namely the satisfaction of military personnel form the service implementatiuon.

The personnel generally builds up some expectations before the service is consumed and has certain predictions or beliefs about what can or is actually expected to happen. The satisfaction with the service may occur during its implementation, but it usually occurs after its consumption. It represents the appreciation of the servicemen for the implementation of the service in relation to their expectations. According to the First Law of Service, satisfaction with the service is met when the perceived performance of the service coincides or exceeds the expectations, namely: [8]

\section{Satisfaction $=$ Perception $\geq$ Expectations}

In order to achieve a high level of satisfaction, outsourcing service providers must above all provide excellent quality, which is the main concern of military personnel related to meeting their expectations. Therefore, it is necessary to make continuous meetings with the service providers and to clarify, by means of a survey, whether or not there is a discrepancy between the views of the military and those of the external suppliers. Consumers are fascinated when their perception of working with the service company exceeds their expectations. This is a crucial issue as the service provider develops and performs the service based on their views and the experience with previous customers, as well as their positive or negative feedback on service consumption. The question now arises whether this experience exceeds, coincides or is below the expectations of the military and is essential for the future relationship between the Armed Forces and the external suppliers of outsourcing services. Almost always, each service provider promises something in the messages in their service advertisement, which is then a basic test of confidence. However, the practice shows that a large number of suppliers "do not respect" their promises, which results in a low level of satisfaction.

All the aforementioned leads to the conclusion that, in order to achieve the goal, namely the full satisfaction of the military, it is necessary to prepare a precise and specific design of the service so that it is effectively implemented.

Undoubtedly, the full satisfaction of the servicemen from the outsourcing service will be directly dependent on the high performance evaluation given by them. However, it should be noted here that for certain types of services, such as the 
organisation of catering to servicemen, factors such as healthy eating, nutritional status, efficiency, balanced nutrition, organisational features and rationing should be considered in addition to consumers' personal perceptions. The impact of these factors on nutrition has been addressed by Glushkov. [2,3,4]

The development of a proper design of the outsourcing service is an important element of the entire outsourcing process and, in order to be successful and meet the requirements of the Armed Forces personnel, the following aspects need to be considered:

$\checkmark$ role of the military personnel;

$\checkmark$ provision of sufficient equipment;

$\checkmark$ location of service implementation;

$\checkmark$ type and functional suitability of the service;

$\checkmark$ skills of the military unit personnel involved in the service execution;

$\checkmark$ prioritisation of individual services, if any;

$\checkmark$ communication with the external contractor.

The effectiveness analysis of oursourcing services is a mandatory and concluding stage of the use of such services.

\section{Methodology for analysis and evaluation of the effectiveness of outsourcing services.}

Against the background, it can be concluded that the evaluation of the effectiveness of outsourcing services reflects the relationship between the final results obtained and the costs incurred. On this basis, the content of a methodology for analysis and evaluation of the outsourcing effectiveness, should include the following phases:

Phase 1: Identification and analysis of the needs for outsourcing services. Specifying the activities of each outsourcing service.

Phase 2: Defining the objectives to be achieved. For each individual activity of the outsourcing service a system of indicators is determined to establish the effectiveness of their use.
Phase 3: Establishing the value of the specified evaluation indicators for the individual outsourcing service activities.

Phase 4: Calculation of the effectiveness of the provided outsourcing service.

Phase 5: Development of an analysis of the effectiveness of outsourcing the service.

In determining the effectiveness of outsourcing services, it is necessary to take into account the actual status of the following elements:

1. Planning the outsourcing service and linking it both with the implementation of the legislation and with the strategic targets and priorities of the Bulgarian Armed Forces units;

2. Analysis of the performance of the individual outsourcing service activities;

3. Legitimate spending of resources;

4. Analysis of the activity of the personnel involved in the outsourcing process;

5. Identifying the risks/obstacles related to outsourcing the service and selection of measures for prevention and early detection of the causes leading to violations as well as for counteracting corruption and offences.

The reporting of these elements can be done by the verification of:

$\checkmark$ the documentation related to the planning and implementation of the outsourcing service;

$\checkmark$ the internal normative acts of the unit;

$\checkmark$ the implementation of various laws, ministerial orders and other instructions;

$\checkmark$ organisation of document turnover;

$\checkmark$ the analyses and reports on the results of the implementation;

$\checkmark$ the compliance with the principles of openness and accessibility, responsibility and accountability;

$\checkmark$ the compliance with the Protection of Classified Information Act.

On the basis of the objective findings of the actual situation, an analysis is performed to assess the effectiveness of outsourcing services in the respective unit. This analysis compares the strengths and weaknesses, reports the execution of the service and the degree of achieving the objectives and 
priorities, as well as the compliance with the law.

On the basis of this analysis, the areas of the outsourcing service that need improvement are defined, the causes leading to violations are identified, and proposals/measures for improvement of the outsourcing service are formulated, including to remove the causes of the breaches.

The evaluation of the effectiveness of outsourcing services in the structures of the Bulgarian Armed Forces is a fundamental methodological activity when deciding on the transfer of services to an external provider. [9]

The choice of performance indicators is the initial stage of the use of such services prior to preparation, drafting the contract and the transfer of the designated services. The striving to improve the effectiveness of outsourcing services ensures to a certain extent the fulfillment of the requirements and needs of the servicemen. By performing effectiveness evaluation and analysis, the continuous improvement of the service quality control system is carried out. [1] This is presented in Figure 1.

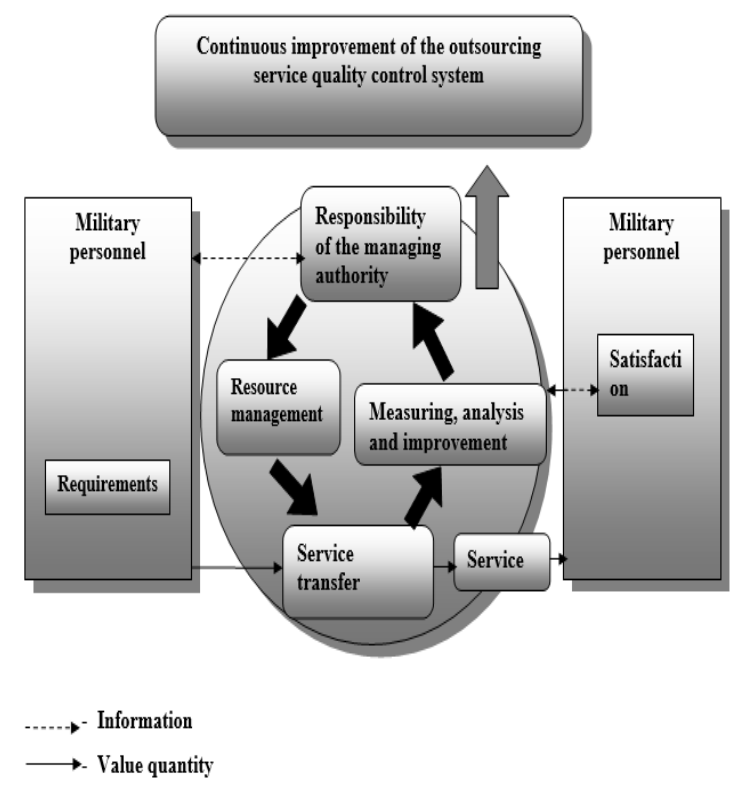

Figure 1: System for service quality control

It is evident that the military are determinant because, on the one hand, they provide values and data in the form of requirements and, on the other, they provide information for analysis, measurement and observation of their satisfaction.

The elements included in the circle of the figure include the following criteria:

$\checkmark$ responsibility for the overall management of the outsourcing process - this encompasses the policy on quality, the objectives and planning, the communication and system flexibility;

$\checkmark$ resource management processes - they include personnel, infrastructure, working environment;

$\checkmark$ processes of service transfer - these cover planning, definition of conditions and requirements, negotiation;

$\checkmark$ evaluation, analysis and improvement processes - these include monitoring, measurement and management of outsourcing services, data analysis, actions on reducing deviations and improvement.

The consecutive linking of the four elements demonstrates their dependence from one another. It is clear that the application of the methodology for evaluation of the effectiveness of outsourcing services, hence improving the quality management system, is the basis for resource management.

\section{Conclusion:}

The analysis of the effectiveness of outsourcing allows to determine whether: [7]

$\checkmark$ the quality control system is adequate;

$\checkmark$ the resources are optimally distributed;

$\checkmark$ the outsourcing service is implemented at a good cost and with good quality for the personnel of the Bulgarian Armed Forces.

The methodology for analysis and evaluation of the effectiveness of outsourcing services is only a means of monitoring the effective implementation and the adherence to the contractual relations. The priority is the strategy chosen for the respective services, as well as the 
objectives for its achievement in the most effective way.

It should be noted that achieving the desired results and increasing the efficiency of outsourcing services in the Bulgarian Armed Forces will also depend on the level of qualification and the management style of the logistics officers who are directly involved in the outsourcing process. The potential effectiveness of the managerial qualities of the future logistics leaders of the Bulgarian Armed Forces is addressed by Hristov and Glushkov. [5]

\section{References}

[1] Bulgarian Standard БДС ЕN ISO 9001:2015 “Quality Control Systems”. Requirements.

[2] Glushkov, P. Food Supply and Nutrition in the Bulgarian Army. Land Forces Academy Review, Vol. XXII, No 4(88), 2017, pages 213-219

[3] Glushkov, P. Use of Linear Optimisation Model in Defining the New Standards for the Preparation of Food for Servicemen in Preparation for Participation in Peacekeeping Operations. The 23rd International Conference Knowledge-Based Organization, Volume XXIII No 2, pages 65-70.

[4] Glushkov, P. A Study of Nutrition and the Nutritional Status of Servicemen, Assessed on the Basis of Anthropometric Indicators. The 23rd International Conference Knowledge-Based Organization, Volume XXIII No 2, pages 298-302.

[5] Hristov, N. Glushkov, P. Comparative Analysis of the Management Activity Training of the Cadets, Studying in the Logistics Specialisations. Proceedings of INTCESS20185th International Conference on Education and Social Sciences 5-7 February 2018Istanbul, Turkey, pages 582-588.

[6] Hristov, N. Glushkov, P. Some Aspects Regarding the Display of the Organisational Activity at Work of the Logistic Officers. Proceedings of INTCESS2018- 5th International Conference on Education and Social Sciences 5-7 February 2018Istanbul, Turkey, pages 187-193.

[7] Mironova, N. D., "Communications as a Factor for Quality in Continuous Professional Training”, International Conference UNWE, 2005, p. 71-85.

[8] Mudie, P. and Pirrie A., "Services Marketing Management", Butterworth- Heinemann, 2006, p. 6.

[9] Nichev, N. "Theoretical Foundations of Military Logistics - Organisation of Logistic Support”, Vasil Levski National Military University, Veliko Tarnovo, 2011, pp. 19-21.

[10] Nichev, N. "Risk Management in the Decision Making Process Concerning the Use of Outsourcing Services in the Bulgarian Armed Forces', International Conference Knowledge-Based Organization, Vol. XXIII, No 1, 2017, Nicolae Balcescu Land Forces Academy Publishing House, Sibiu, Romania, pages: 405-410, ISSN 1843-682X, ISBN 978-973-153-273-8.

[11] Winter, F. and Thomas, H. "Can Customers Be Segmented on The Basis of Their Customer Service Quality Expectations", The Journal of Market Segmentation, Industrial Marketing Management, Vol.9, 1980, pp. 201-3. 